\title{
Gestão do relacionamento em uma indústria de peças plásticas da cadeia automotiva
}

\author{
Relationship management in a plastic part industry of the \\ automotive chain
}

\author{
Eliacy Cavalcanti Lélis ${ }^{1,2}$ \\ Alexandre Tadeu Simon ${ }^{3}$
}

\begin{abstract}
Resumo: A gestão da cadeia de suprimentos considera vários aspectos das relações entre organizações. A gestão do relacionamento na interface fornecedor-cliente é um dos elementos analisados que abrangem variáveis complexas, as quais podem afetar a sustentação de elos críticos da cadeia produtiva. Esta pesquisa delimita-se ao estudo da gestão do relacionamento em uma cadeia de suprimentos do setor automotivo. O objetivo deste artigo é estudar a gestão do relacionamento em uma indústria de peças automotivas de plástico de São Paulo. A metodologia de pesquisa utiliza a pesquisa de campo, limitada a um estudo de caso, cuja análise utiliza uma metodologia de avaliação proposta por Simon (2005). Essa metodologia avalia o grau de aderência da gestão do relacionamento de uma empresa ao modelo de gestão da cadeia de suprimentos de Cooper, Lambert e Pagh (1997). Os resultados mostram os fatores de gerenciamento do relacionamento que contribuem para a eficiência da gestão da cadeia e destacam aspectos que podem ser melhorados em relação à colaboração na cadeia, no que se refere à comunicação informal e falta de planejamento conjunto entre os parceiros da empresa.
\end{abstract}

Palavras-chaves: Gestão do relacionamento. Fornecedor. Cliente. Cadeia automotiva.

\begin{abstract}
Supply chain management includes several aspects of relationships between organizations. The relationship management of supplier-customer interface is one of the elements analyzed that encompass complex variables that can affect the support of critical links in the production chain. This research investigates the relationship management in a supply chain of the automotive sector. The objective of this paper is to study the relationship management in an industry of automobile plastic parts in São Paulo, Brazil. The field research method with a single case study, based on the method of Simon (2005), was used. This method evaluates the level of adherence of the relationship management of an enterprise to the supply chain model proposed by Cooper, Lambert and Pagh (1997). The results show the relationship management factors that contribute to the efficiency of supply chain management and highlight the aspects that can be improved concerning the chain collaboration in terms of informal communication and lack of joint business planning between the company partners.
\end{abstract}

Keywords: Relationship management. Supplier. Customer. Automotive chain.

\section{Introdução}

O ambiente externo das organizações sofre constantes mudanças, que foram se intensificando no decorrer dos anos com o avanço da tecnologia e da economia globalizada. Essas mudanças impulsionam as organizações a reverem suas estratégias, seus processos, suas formas de gestão e seus indicadores de desempenho para se adequarem aos novos contextos competitivos.

Alguns setores produtivos passaram a se organizar de forma mais sistemática, adotando o conceito de cadeia de suprimentos para conseguirem vantagem competitiva, nessa situação destaca-se a indústria automotiva, que vem mostrando resultados significativos com a gestão da cadeia de suprimentos, investindo na colaboração entre empresas e em tecnologias (BINDER; CLEGG, 2007; DINIZ; FABBE-COSTES, 2007).

Diversos estudos mostram iniciativas e práticas da gestão da cadeia de suprimentos, com uma diversidade ampla de opções para o gestor contemporâneo

\footnotetext{
${ }^{1}$ Universidade Presbiteriana Mackenzie - MACKENZIE, CEP 01302-907, São Paulo, SP, Brasil, e-mail: eliacylelis@gmail.com

${ }^{2}$ Universidade Nove de Julho - UNINOVE, CEP 02117-010, São Paulo, SP, Brasil

${ }^{3}$ Programa de Pós-graduação em Engenharia de Produção - PPGEP, Universidade Metodista de Piracicaba - UNIMEP, Rod. Luis Ometto (SP 306), Km 24, CEP 13450-000, Santa Bárbara d'Oeste, SP, Brasil, e-mail: atsimon@ unimep.br
}

Recebido em 6/1/2011 — Aceito em 29/11/2012

Suporte financeiro: Nenhum. 
desenvolver relações interorganizacionais que podem reestruturar e consolidar os laços com os fornecedores (PIRES, 2009; SIMON, 2005; COUSINS et al., 2008).

Cada vez mais as empresas estão adotando a estratégia de horizontalização ou desintegração vertical, investindo mais no seu negócio principal (core business) e terceirizando várias operações (MARTINS; ALT, 2009; MOURA, 2009). Isso tem destacado a relação com os fornecedores, que se tornou uma rede de network com uma estrutura mais complexa, principalmente nos casos onde o suprimento envolve operações globalizadas (HALL; BRAITHWAITE, 2001; MONCZKA et al., 2002; DORNIER et al., 2000).

Dornier et al. (2000) destacam que a tendência é a redução no número de fornecedores, com a reestruturação da base de fornecedores e a consolidação dessa base. Essa consolidação depende da gestão do relacionamento para o desenvolvimento de um sistema colaborativo e de confiança.

A gestão do relacionamento com fornecedores chama a atenção do meio acadêmico e do mercado pela sua importância para os custos, para a imagem e para a qualidade dos produtos e serviços da organização. Quanto mais presente a estratégia de horizontalização no suprimento da linha de produção, mais dependente ela é dos fornecedores (MARTINS; ALT, 2009). A gestão do relacionamento com o cliente trata da interface da empresa com seu mercado consumidor e, dependendo da etapa de produção dessa empresa, esse cliente pode ser um consumidor intermediário (empresa que fornece para cliente-empresa) ou um consumidor final (empresa que fornece para cliente).

Este artigo estuda a gestão do relacionamento em uma indústria de peças automotivas de plástico de São Paulo. A metodologia de pesquisa utiliza a pesquisa de campo, limitada a um estudo de caso, cuja análise utiliza uma metodologia de avaliação proposta por Simon (2005). Essa metodologia avalia o grau de aderência da gestão do relacionamento de uma empresa ao modelo de gestão da cadeia de suprimentos proposto por Cooper, Lambert e Pagh (1997). O estudo está limitado a um caso realizado em uma indústria de plásticos fornecedora de peças automotivas para empresa-cliente que é montadora de um módulo ou sistema do veículo (modulista ou sistemista).

\section{Gestão dos processos de negócios da cadeia de suprimentos}

O termo cadeia é comumente utilizado para as terminologias: cadeia produtiva e cadeia de suprimentos. A diferença é que cadeia produtiva refere-se ao conjunto de atividades que representam genericamente um setor industrial e cadeia de suprimentos é mais abrangente, envolve todas as atividades associadas com o movimento de bens, desde o estágio da matéria-prima até o usuário final (PIRES, 2009).

As operações da cadeia revelam a real capacidade de execução da organização em relação às promessas oferecidas ao mercado, porém sua efetividade depende de como é conduzida a gestão da cadeia de suprimentos (SHETH; SHARMA, 2007).

Vale destacar a seguir alguns conceitos clássicos da área, mostrando diferentes perspectivas para a gestão da cadeia de suprimentos.

Para Slack, Chamber e Johnston (2009), a gestão da cadeia de suprimentos é a gestão da interconexão das empresas que se relacionam por meio de ligações à montante e à jusante entre os diferentes processos, para a produção de valor na forma de produtos e serviços entregues ao consumidor final. Esse conceito destaca as relações entre as organizações, com uma visão holística dos processos.

Chopra e Meindl (2003) consideram que a gestão da cadeia abrange os fluxos entre os estágios da cadeia para maximizar a lucratividade total. Essa perspectiva valoriza a rentabilidade das organizações, mas traçando a relação com os fluxos dos processos.

Lambert, Stock e Ellram (1998b) tratam da gestão da cadeia de suprimentos considerando a integração de todos os processos chave do negócio. Essa visão de negócio e processos reúne as perspectivas de Chopra e Meindl (2003) e Slack, Chamber e Johnston (2009).

A reunião desses conceitos mostra que a gestão da cadeia de suprimentos está estruturada em processos localizados nas organizações que compõem a cadeia de suprimentos, visando agregar valor ao negócio para viabilizar a rentabilidade de forma competitiva. Isso mostra a importância que a gestão da cadeia ou SCM - Supply Chain Management tem para o mercado e para o meio acadêmico.

Para Dornier et al. (2000), a gestão da cadeia de suprimentos pode atuar como entidade interfuncional, como usuária estratégica de estoque e outros recursos produtivos e como integradora e coordenadora das atividades de produção e logística.

Conforme Slack, Chamber e Johnston (2009), o comportamento da cadeia de suprimentos é definido pela sua política de gestão, para que as operações na cadeia sejam apropriadas às necessidades dos consumidores finais. Para maximizar a lucratividade da cadeia, os principais objetivos da gestão da cadeia de suprimentos são: focalizar na satisfação dos clientes finais; formular e implementar estratégias baseadas na obtenção e retenção de clientes finais; e gerenciar a cadeia de maneira eficaz e eficiente.

Entretanto, os desafios para atingir esses objetivos variam com o tipo de atividade produtiva e, em muitos casos, podem-se enfrentar essas barreiras:

- Em longas cadeias envolvendo vários negócios não é fácil coordenar toda a cadeia, 
principalmente quando parte da cadeia atende a dois ou mais conjuntos de clientes finais;

- Conflitos na interface do relacionamento entre clientes e fornecedores das unidades produtivas.

A Figura 1 interliga esses pressupostos para a gestão da cadeia de suprimentos.

Alves Filho et al. (2004) lembram que a gestão da cadeia de suprimentos deveria presumir alguns pressupostos em relação:

(1) Ao ambiente competitivo: Competição deve ocorrer entre cadeias e não mais entre empresas isoladas;

(2) Ao alinhamento estratégico das organizações e à repartição de ganhos: As estratégias competitivas devem estar alinhadas;

(3) À estrutura da cadeia: Os fornecedores devem estar organizados hierarquicamente, com um número relativamente pequeno de fornecedores em cada nível da cadeia e os fluxos de materiais, serviços e informações devem ser bidirecionais, ocorrendo entre todas as empresas pertencentes à cadeia;

(4) Às relações entre as empresas na cadeia: As relações entre empresas devem ser cooperativas e de longo prazo.

Os conceitos sobre parceria, relacionamento de longo prazo, indicadores de desempenho integrados, comunicação em tempo real e integração nas atividades são alternativas que podem ser exploradas na busca pelo alinhamento estratégico na gestão da cadeia de suprimento (JOSHI et al., 2003; HULT; KETCHEN JUNIOR; ARRFELT, 2007).

Estudos sobre a gestão da cadeia de suprimentos têm revelado vários conceitos, modelos e abordagens, e mesmo com tantas perspectivas diferentes, muitas dessas diferenças se complementam, trabalhando as questões referentes ao fluxo, cliente e valor

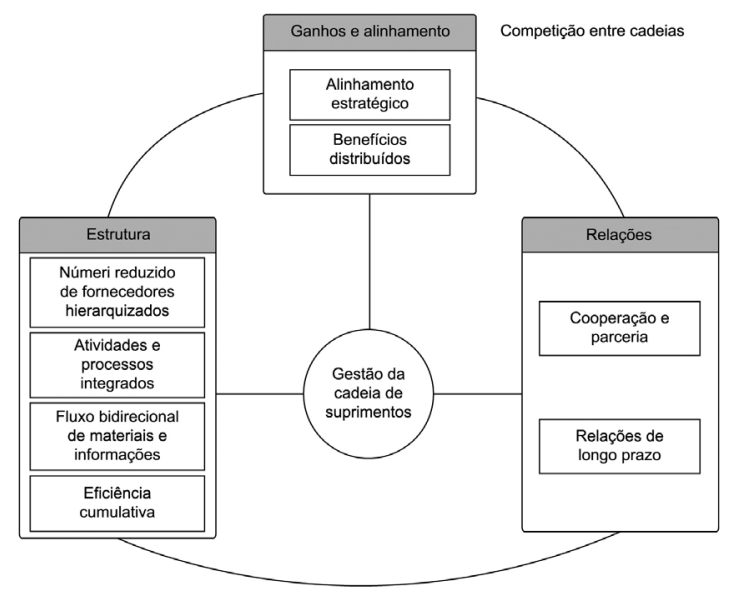

Figura 1. A GCS e seus pressupostos (ALVES FILHO et al., 2004). sempre destacando a relação entre as organizações (KOTZAB et al., 2005; ALVES FILHO et al., 2004).

Diversos modelos de gestão da cadeia de suprimentos são utilizados como base de referência para o entendimento do funcionamento complexo e dinâmico. Essa gestão varia com o tipo de segmento e o número de organizações envolvidas nesse negócio, por isso há tantas lacunas e oportunidades de estudo nessa área.

Pires (2009) apresenta quatro modelos de gestão que tratam da integração de processos:

\section{a) Modelo de Cooper, Lambert e Pagh}

Para Pires (2009), o modelo enfatiza a natureza inter-relacional da SCM com base em três elementos: (1) estrutura da SC - Supply Chain, (2) processos de negócios da SC e (3) componentes gerenciais da SCM (Figura 2).

\section{b) Modelo do Supply-Chain Council (SCC) - SCOR}

De acordo com Pires (2009), o SCOR - SupplyChain Operations Reference é um modelo lançado em 1997 que contém dois elementos essenciais: (1) os processos de negócios básicos: planejar, abastecer, produzir, entregar e retornar; e (2) os níveis de detalhamento do modelo: os três primeiros referentes a processos de projeto e o quarto ao processo de implementação (Figura 3).

O SCC (SUPPLY..., 2011) explica que os processos do SCOR contêm:

- Métricas de desempenho;

- Descrição padronizada de gerenciamento de processos;

- Práticas gerenciais que produzem alto desempenho;

- Requisitos de treinamento e hablidades para as pessoas.

c) Modelo da MSU - Michigan State University

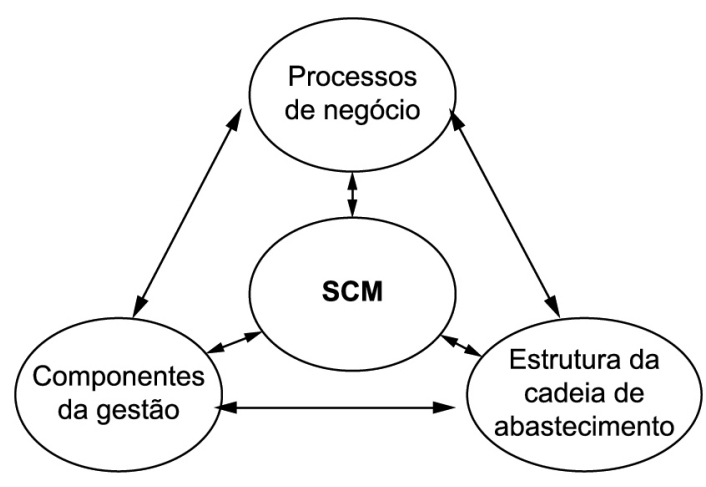

Figura 2. Elementos do modelo SCM (traduzido de LAMBERT; COOPER; PAGH, 1998a). 
O programa demonstra a origem multidisciplinar e multifuncional da SCM e sugere que a SCM tem oito pilares:

(1) Projeto e reprojeto do produto;

(2) Projeto e reprojeto de processos;

(3) Medição de desempenho;

(4) Gestão da capacidade;

(5) Planejar;

(6) Adquirir/abastecer;

(7) Fazer/produzir;

(8) Entregar.

d) Modelo do IMD - International Institute for Management Development

O IMD propõe quatro frentes básicas de trabalho em SCM:

(1)Execução do processo produtivo de forma perfeita, sem falhas;
(2) Movimento de SCM para DCM - Demand Chain Management;

(3) Implementação de parcerias;

(4) Outsourcing e desenvolvimento da base de fornecedores.

Dentre esses modelos, Simon (2005) destaca a relação entre os modelos mais conhecidos: o SCC e o de Cooper, Lambert e Pagh (Quadro 1).

Simon (2005) mostra que os modelos citados no Quadro 1 são muito utilizados nas pesquisas, sendo muito conhecidos no meio acadêmico, mas, nesta pesquisa, o modelo de referência é o indicado por Cooper, Lambert e Pagh (1997), mostrado na Figura 4, pois ele trata a gestão do relacionamento com fornecedores de acordo com o enfoque proposto pelo objetivo desta pesquisa.

Os processos de negócio precisam de coordenação e visibilidade e a questão até que ponto a cadeia de suprimentos pode ser administrada depende de

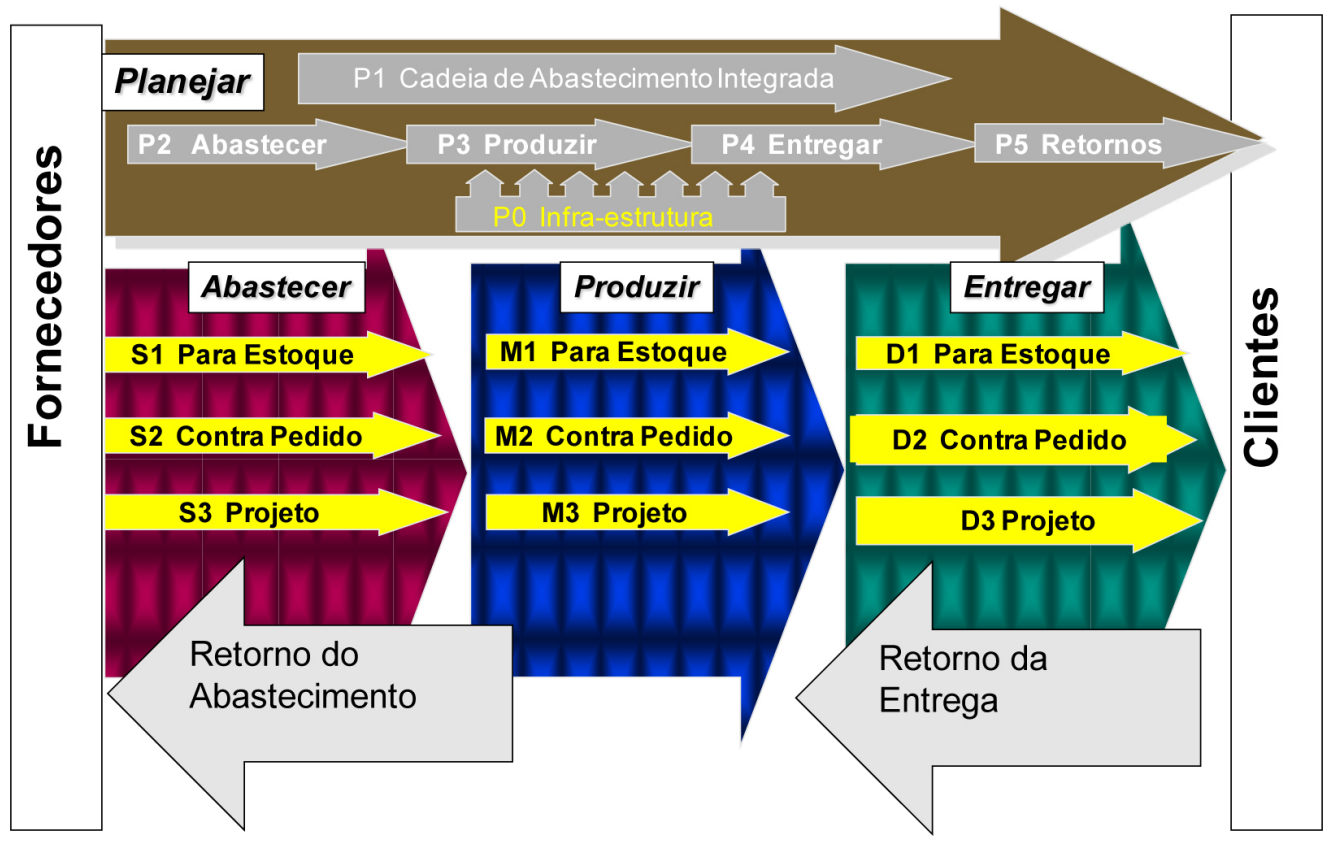

Figura 3. Modelo SCOR (adaptado de STEPHENS, 2001).

Quadro 1. Relação entre os processos de negócio do modelo de Cooper, Lambert e Pagh e o modelo SCOR.

\begin{tabular}{|l|l|}
\hline \multicolumn{1}{|c|}{ Cooper, Lambert e Pagh } & SCOR \\
\hline Gestão do relacionamento com clientes & Planejar \\
\hline Gestão do serviço ao cliente & Entregar \\
\hline Gestão da demanda & Entregar \\
\hline Atendimento do pedido & Entregar \\
\hline Gestão do fluxo de manufatura & Produzir/Planejar \\
\hline Gestão do relacionamento com os fornecedores & Abastecer/Planejar \\
\hline Desenvolvimento e comercialização do produto & Não contempla \\
\hline Gestão dos retornos & Retornos/Planejar \\
\hline
\end{tabular}

Fonte: Simon (2005). 


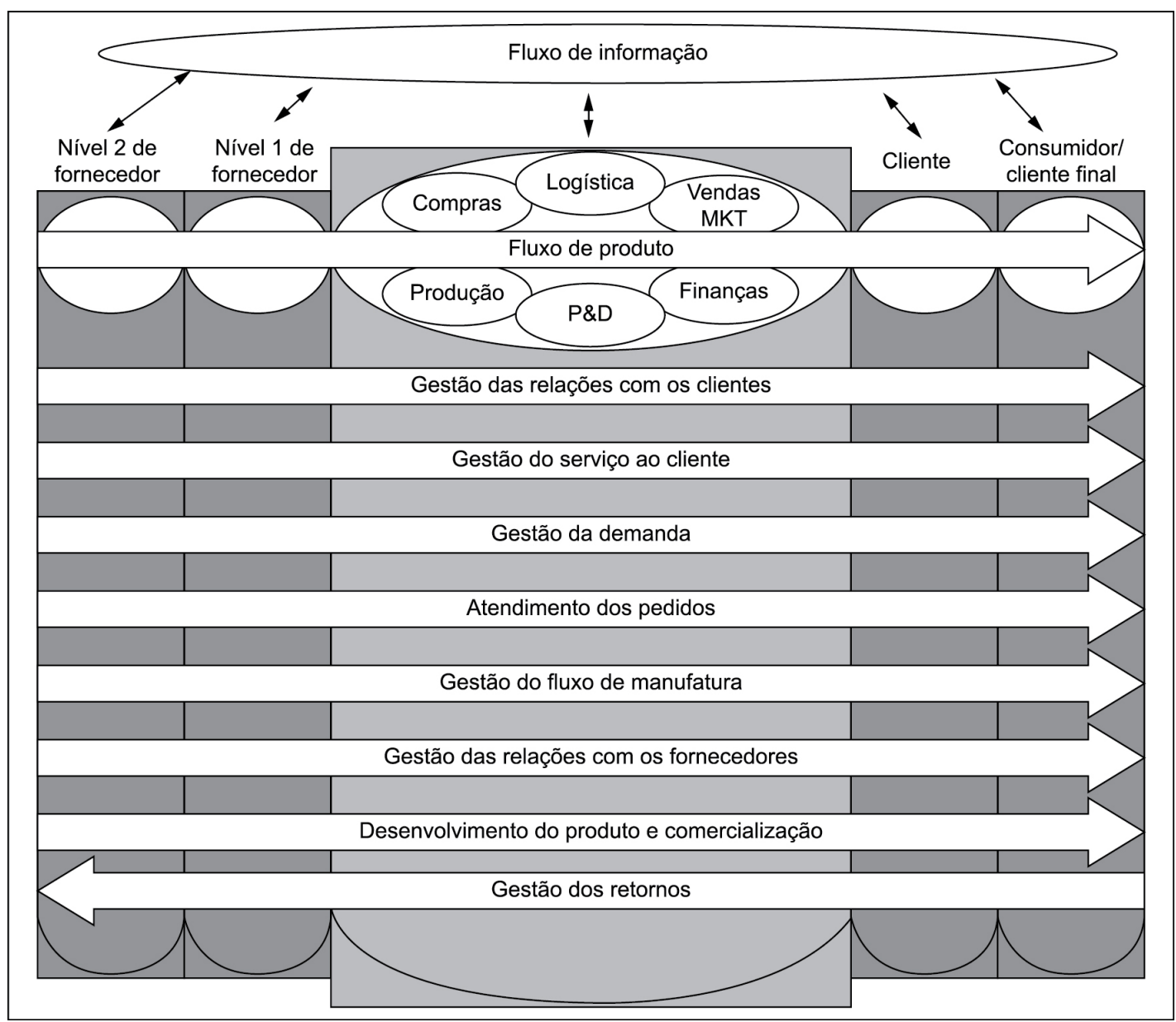

Figura 4. Estrutura da Gestão da Cadeia de Suprimentos (LAMBERT; COOPER; PAGH, 1998a).

fatores como: complexidade do produto, número de fornecedores envolvidos no negócio e a disponibilidade de matéria-prima. A dinâmica natural do ambiente de negócios requer um gerenciamento que monitore e avalie o desempenho dos processos da cadeia de suprimentos com regularidade e frequência.

Lambert, Stock e Vantine (1998c) sugerem quatro etapas para a implantação desse modelo:

1) Identificar os processos chave do negócio na cadeia de abastecimento e subatividades primárias;

2) Como cada função e entidade se relaciona a cada processo chave do negócio na cadeia de abastecimento;

3) Identificar interações entre processos chave no negócio na cadeia de abastecimento;

4) Identificar componentes chave da administração da cadeia de abastecimento.

\section{Gestão do relacionamento}

É raro uma empresa participar apenas de uma cadeia de fornecimento, por isso a cadeia parece uma "árvore" e a questão é quantos galhos e raízes precisam ser administrados. Se o produto exigir um grande número de componentes, então um grande número de fornecedores está envolvido nessa cadeia, levando à necessidade de um gerenciamento que possa transformar relacionamentos em parcerias. Provavelmente, as empresas escolherão o nível de parceria adequado para cada elo da cadeia produtiva, com diferenças no nível de coordenação e integração.

As parcerias são consideradas sob medida para a geração de desempenho superior em relacionamentos nos quais o fornecedor não teria condições de conseguir esse nível de resultado sozinho. Normalmente, esse tipo de relação tem os seguintes elementos (LAMBERT; STOCK; VANTINE, 1998c):

- Planejamento;

- Controles operacionais conjuntos;

- Comunicações;

- Riscos/recompensas compartilhados;

- Confiança e comprometimento;

- Estilo de contrato que estimula o médio ou longo prazo;

- Escopo de indicadores de desempenho ampliado;

- Investimento financeiro em tecnologia e infraestrutura. 
Quanto mais elementos motivadores, maior a chance de sucesso na parceria, entretanto, a parceria custa caro na implementação e nem todos os relacionamentos podem ser parceria. Portanto, é imprescindível que as estratégias de parceria sejam subordinadas à estratégia corporativa (ou empresarial) como um todo.

Vivaldini e Pires (2010) reforçam essa questão ao afirmar que o uso de novos métodos e ferramentas tecnológicas auxilia a administração no planejamento, previsão e reposição, facilitando a troca e distribuição da informação na cadeia de suprimentos. Cada membro é levado a repensar o caminho para alavancar o relacionamento com seus parceiros comerciais, com uma visão de valor que não pode ficar restrita somente aos supridores da primeira camada, mas também aos demais fornecedores da segunda, terceira etc. Afinal, estão todos no mesmo processo de negócio.

Para Kakabadse e Kakabadse (2002), a promoção de um relacionamento com qualidade pode envolver diversas habilidades:

- Desenvolver um entendimento compartilhado entre parceiros;

- Reconhecer o nível de cultura entre os parceiros;

- Desenvolve relações de alta qualidade;

- Gerenciar relacionamentos por meio de mudanças nas obrigações contratuais;

- Gerenciar os relacionamentos baseados em consórcio;

- Motivação do staff e da gestão de nível operacional e tático;

- Desenvolver os empregados para melhorar seu desempenho.

Quando o termo parceria entre os fornecedores é cultivado, espera-se que fornecedores e consumidores cooperem, compartilhando recursos e habilidades para alcançar benefícios conjuntos que, provavelmente, sozinhos não conseguiriam (SLACK; CHAMBER; JOHNSTON, 2009). As parcerias que demandam um grau de entendimento e confiança mútua no processo de aquisição são relações conhecidas como comakership, nelas o cliente irá atuar nos aspectos que possam lhe trazer vantagens competitivas (MARTINS; ALT, 2009).

Com um relacionamento de parceria, a integração e a cooperação na organização e entre as organizações da cadeia de suprimentos são as ideias fundamentais da gestão moderna. O alinhamento das operações na cadeia produtiva sincroniza os sistemas e métodos do processo decisório no planejamento e controle. Spekman, Kamauff Junior e Myhr (1998) conduziram uma pesquisa em 22 cadeias de suprimentos de vários setores e mostram que a cooperação não é a única opção de relacionamento:

- Negociações: Discussões sobre preço e relacionamento como adversários;
- Cooperação: Poucos fornecedores e contratos de longo prazo;

- Coordenação: Conexão via TIC - Tecnologia da Informação e da Comunicação e compartilhamento de informações;

- Colaboração: Integração na cadeia de suprimentos; planejamento conjunto e compartilhamento de tecnologia.

O relacionamento colaborativo entre o fornecedor e o cliente é um dos componentes mais difíceis de obter, porque esse tipo de relação não se limita a uma simples aliança ou parceria, abrangendo o aspecto da confiança mútua (BERTAGLIA, 2009).

Não se constrói a confiança da noite para o dia, é preciso tempo, um prazo longo e, por isso, associam-se os relacionamentos de longo prazo a relacionamentos colaborativos, com uma base consolidada, estável de participantes que procuram se conhecer e estabelecer vínculos mais profundos entre si. Hines (2004) traça a relação entre a estrutura da cadeia e seus relacionamentos, evidenciando o poder das decisões de compras nos fluxos dos processos chaves. Ele apresenta três tipos de relacionamento: comercial (ênfase no preço); parcerias (ênfase nos relacionamentos) e integração (joint venture e integração vertical).

Zhang, Viswanathan e Henke Junior (2011) também estudam o desenvolvimento da confiança na relação comprador-fornecedor em uma pesquisa empírica nas cadeias de suprimentos da indústria automotiva e da indústria de alimentos. Eles observaram que a eficácia na estratégia de comunicação com os fornecedores afeta a confiança do fornecedor na empresa compradora.

Vivaldini e Pires (2010) aprofundaram os conhecimentos sobre os operadores logísticos e o seu papel no processo de suprimentos, destacando a importância da colaboração e da integração entre os fornecedores. Eles apontam as principais atividades colaborativas que podem ser desenvolvidas na relação entre cliente e fornecedor, conforme mostra o Quadro 2.

\section{Gestão do relacionamento na cadeia automotiva}

Diversos estudos procuram explicar a SCM no contexto automotivo, como funciona o fluxo de informações, a relação entre os fornecedores e a tecnologia de suporte da cadeia de suprimentos.

Alguns desses estudos revelam a preocupação e a prática do setor automotivo na reestruturação e consolidação dos fornecedores. Cerra, Maia e Alves Filho (2007) realizaram um estudo em três cadeias de suprimento automotivas que identificou os níveis de relacionamento entre as empresas (Figura 5).

Podem ainda ocorrer casos em que a montadora atua diretamente em seus fornecedores não imediatos 
Quadro 2. Atividades colaborativas.

\begin{tabular}{|c|c|}
\hline Atividades & Conteúdo \\
\hline \multirow{5}{*}{ Compartilhando informação } & Prevendo \\
\hline & - Demanda do cliente \\
\hline & - Necessidade de materiais \\
\hline & Plano de marketing \\
\hline & Capacidade de produção e programação \\
\hline \multirow{3}{*}{ Planejamento conjunto } & Objetivos de produtividade e vendas \\
\hline & Orçamentos \\
\hline & Priorizando metas e objetivos \\
\hline \multirow{5}{*}{ Resolvendo problemas } & Desenvolvendo produtos \\
\hline & Problemas logísticos (embarques, rotas, tamanho de pallet, embalagens etc.) \\
\hline & Suporte de marketing \\
\hline & Controle de qualidade \\
\hline & Análise de custo-benefício \\
\hline \multirow{3}{*}{ Medidas de desempenho } & Baseline e revisão da performance \\
\hline & KPIs \\
\hline & Determinando recompensas e ações corretivas \\
\hline \multirow{3}{*}{ Alavancagem } & Recursos e capacidades \\
\hline & Habilidades e conhecimentos \\
\hline & Especialização \\
\hline
\end{tabular}

Fonte: Min et al. (2005).

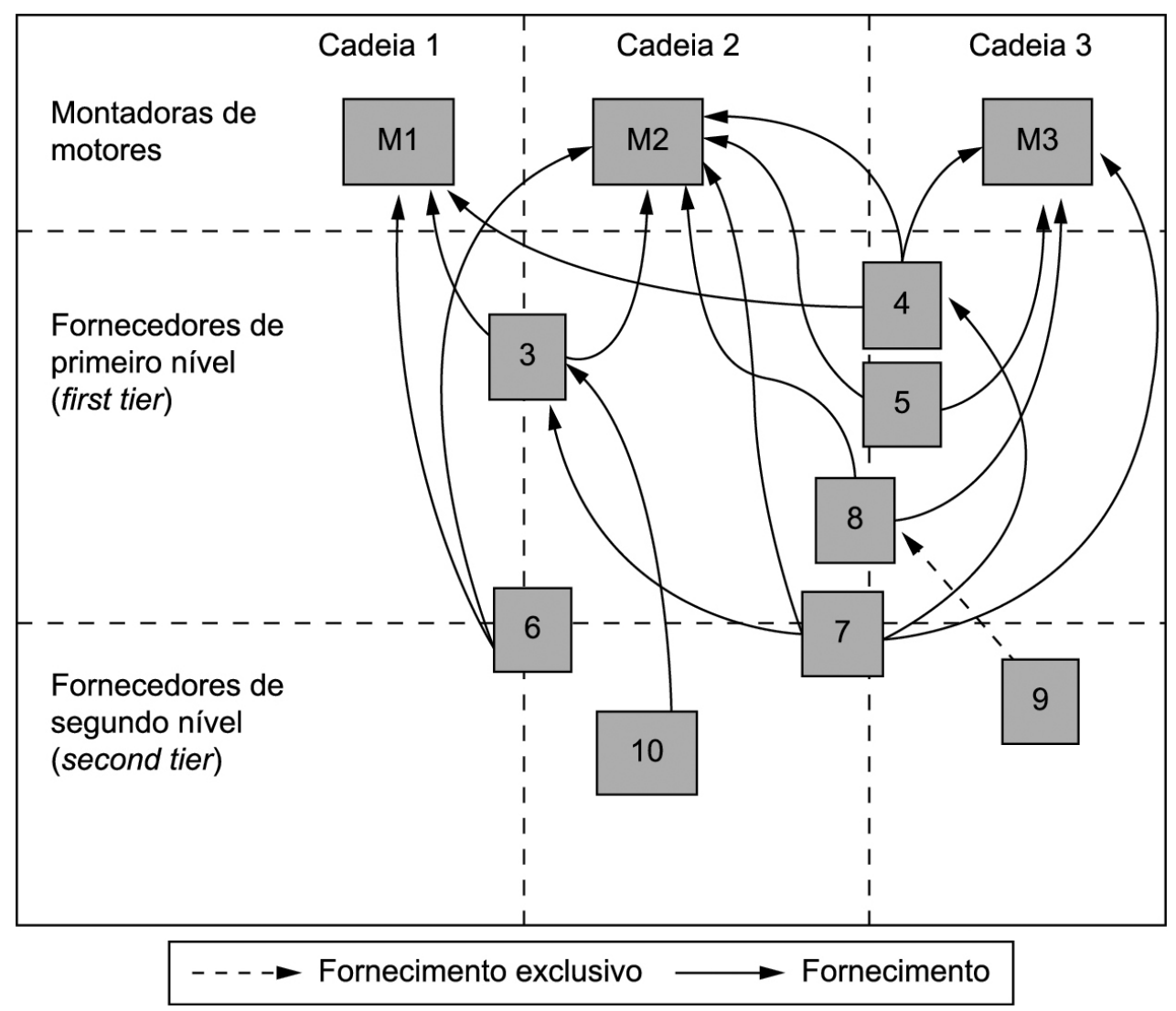

Figura 5. Relações de fornecimento entre as empresas das cadeias de suprimentos (CERRA; MAIA; ALVES FILHO, 2007). 
para obter ganhos em prazos de entrega, preços, ou mesmo melhoria na qualidade dos produtos. Os estudos demonstraram que essas montadoras, apresentadas na Figura 4, têm diferentes níveis de terceirização na fabricação dos componentes para motores.

A gestão do relacionamento no setor automotivo foi estudada por Zirpoli e Caputo (2002), com a análise do processo de reestruturação de fornecedores da FIAT Italiana devido a uma política de outsourcing da montadora, na década de 1990.

A evolução da integração na cadeia foi observada por Towill, Childerhouse e Disney (2002) pela análise de 20 cadeias automotivas europeias. Eles verificaram que 11 dessas cadeias teriam atingido um estágio de integração funcional e que poderiam evoluir para um estágio mais avançado de integração.

Grazidio (2004) apresenta duas estratégias no processo de suprimento na cadeia automotiva: estratégia modular e estratégia convencional. A estratégia modular é um meio de aumentar a eficiência da capacidade de produção em que o fornecedor integrador de primeiro nível é chamado de sistemista e é responsável pela montagem de um módulo de suspensão de um veículo.

A criação do fornecedor sistemista reduziu a base de fornecedores no contato com a montadora, influenciando fortemente o processo de negociação, comunicação, logística, desenvolvimento de projetos, relação contratual e qualidade do processo e do produto.

Correa e Correa (2006) também relatam a experiência da Volkswagen com a estratégia modular, inicialmente na planta de Rezende, Rio de Janeiro, desde 1996. No consórcio modular, os parceiros trabalham dentro da planta da montadora e têm a responsabilidade da montagem do módulo e da conexão desse módulo ao chassi na linha de montagem final.

Prieto e Miguel (2006) apontam a existência da consolidação da cadeia modular automotiva e a progressividade na transferência de valor no desenvolvimento de produtos entre os fornecedores estratégicos (sistemistas) e de segundo nível. Eles observam que vem ocorrendo o desenvolvimento de fornecedores através da capacitação necessária para a mobilidade de conhecimento entre os fabricantes de veículos e os fornecedores sistemistas.

Desse modo, há um fortalecimento das competências que podem gerar benefícios de valor agregados nas atividades do fornecedor de primeiro nível que assume o papel de integrador do sistema. O desenvolvimento e evolução dos fornecedores na progressão de competências são mostrados no Quadro 3.

Essa progressiva transferência de valor das atividades dos clientes para os fornecedores sistemistas implicou em parcerias de longo prazo, desse modo o fornecedor estratégico (integrador) é acionado para desenvolver projeto juntamente com a montadora, numa colaboração que pode reduzir custos e aumentar a qualidade para ambas as partes.

Observa-se que o consórcio modular viabiliza um alinhamento estratégico coordenado pela montadora, delimitando o nível de qualidade e o preço final do produto no mercado. Essa temática é tratada nos estudos sobre governança na cadeia de suprimentos.

O termo governança quase sempre está relacionado às relações de coordenação, cooperação e colaboração. A estrutura de governança refere-se ao grau de hierarquia, liderança e comando na cadeia de suprimentos (PIRES, 2009; SUZIGAN et al., 2007).

A governança na cadeia produtiva trata das relações de poder nas relações dentro da cadeia e pode ser resultado de fortes hierarquias impostas por agentes com poder de comando. Vale salientar que as relações de coordenação dependem de variáveis que afetam o tipo de governança.

\section{Metodologia da pesquisa}

Simon (2005) propôs uma metodologia de avaliação do grau de aderência das empresas ao modelo conceitual de gestão da cadeia de suprimentos de Cooper, Lambert e Pagh (1997). Essa metodologia é chamada AGA (Avaliação de Grau de Aderência) - SCM e aborda todos os processos de negócio.

Como o foco desta pesquisa é a gestão do relacionamento, limitaremos a apresentação dos itens da metodologia referentes à gestão do relacionamento com o cliente e à gestão do relacionamento com o fornecedor.

O questionário utilizado na coleta de dados do estudo de caso está estruturado pela metodologia conforme apresentado nos Quadros 4 e 5 . Os resultados foram tabulados na forma de gráfico de radar.

$\mathrm{O}$ questionário foi aplicado aos gestores e profissionais da área de produção, qualidade, vendas e custos da indústria analisada. A empresa tem duas unidades instaladas que atuam em dois segmentos: automotivo e de utensílios domésticos. Para atender ao objetivo da pesquisa, a aplicação do questionário limitou-se à instalação industrial do setor automotivo.

\section{Resultados da pesquisa}

$\mathrm{Na}$ etapa da cadeia de suprimentos em estudo, essa empresa é fornecedora da segunda camada que abastece o fabricante de peças automotivas para empresa cliente montadora de um módulo ou sistema do veículo (modulista ou sistemista), conforme mostra a Figura 6.

A empresa em estudo é de pequeno porte e foi fundada em 1988, com um processo de injeção de peças técnicas que apresenta soluções tecnológicas para diversos segmentos do mercado interno e externo, 
Quadro 3. Progressividade de competências dos fornecedores da cadeia modular.

\begin{tabular}{|c|c|c|}
\hline EMBRIONÁRIAS & EM DESENVOLVIMENTO & MADURAS \\
\hline \multicolumn{3}{|c|}{ RECURSOS CHAVE } \\
\hline $\begin{array}{l}\text { Baixa capacidade tecnológica } \\
\text { Operações em pequena escala e sem } \\
\text { presença global } \\
\text { Baixa capacidade de gerenciamento } \\
\text { Não possui marca própria }\end{array}$ & $\begin{array}{l}\text { Alta capacidade tecnológica } \\
\text { Operações de média capacidade e } \\
\text { algumas operações fora do país de } \\
\text { origem } \\
\text { Desenvolvendo capacidades de } \\
\text { gerenciamento } \\
\text { Desenvolvendo marca própria } \\
\text { Aloca recursos significativos em } \\
\text { P\&D }\end{array}$ & $\begin{array}{l}\text { Altos níveis tecnológicos } \\
\text { Presença global } \\
\text { Capacidades bem desenvolvidas de } \\
\text { gerenciamento } \\
\text { Importante orientação para P\&D } \\
\text { Habilitação para tornar-se fornecedor } \\
\text { modular e, em alguns casos, } \\
\text { vendedor de módulos } \\
\text { Marca própria ou família de produtos } \\
\text { de marca }\end{array}$ \\
\hline \multicolumn{3}{|c|}{ POTENCIALIDADES DE RELACIONAMENTO PRA O FORNECIMENTO DE PRODUTOS E SERVIÇOS } \\
\hline $\begin{array}{l}\text { Limitado ao direcionamento } \\
\text { realizado por seus clientes } \\
\text { Pouco posicionados para acomodar } \\
\text { as mudanças necessárias para a } \\
\text { produção modular }\end{array}$ & $\begin{array}{l}\text { Desenvolvendo relacionamentos para } \\
\text { fornecimento } \\
\text { Representado em várias regiões } \\
\text { chave de produção com limitada } \\
\text { presença na cadeia de suprimentos }\end{array}$ & $\begin{array}{l}\text { Deve controlar elementos chave } \\
\text { da cadeia de suprimentos, } \\
\text { particularmente onde o fornecedor } \\
\text { está desenvolvendo sua posição } \\
\text { como fornecedor modular }\end{array}$ \\
\hline \multicolumn{3}{|c|}{ POSICIONAMENTO ESTRATÉGICO } \\
\hline $\begin{array}{l}\text { É um ator reativo sem visão de } \\
\text { longo prazo sobre as mudanças que } \\
\text { ocorrem no setor }\end{array}$ & $\begin{array}{l}\text { É um ator proativo que está ciente } \\
\text { das mudanças chave do setor e } \\
\text { está se posicionando para prover } \\
\text { mudanças adequadas }\end{array}$ & $\begin{array}{l}\text { Tem foco bem definido sobre fatores } \\
\text { chave de mudança que ocorrem no } \\
\text { setor e já iniciou investimentos para } \\
\text { se posicionar como ator importante } \\
\text { nesse ambiente modular }\end{array}$ \\
\hline \multicolumn{3}{|c|}{ RELACIONAMENTOS INTERORGANIZACIONAIS E OPERAÇÕES } \\
\hline $\begin{array}{l}\text { Os clientes definem os termos e } \\
\text { condições e impõem penalidades } \\
\text { pelo não cumprimento } \\
\text { Peças estão sujeitas a inspeções do } \\
\text { cliente } \\
\text { Foco em diversos setores } \\
\text { Não possui flexibilidade } \\
\text { operacional } \\
\text { Não possui fatores considerados } \\
\text { ganhadores de pedido }\end{array}$ & $\begin{array}{l}\text { Desfrutam de confiabilidade quanto } \\
\text { aos contratos estabelecidos com seus } \\
\text { clientes } \\
\text { Proporcionam qualidade assegurada } \\
\text { às peças em um sistema JIT } \\
\text { Foco em um único setor } \\
\text { Flexibilidade operacional } \\
\text { Pedido ganhador provavelmente } \\
\text { define-se por: presença global } \\
\text { e habilidade de prover soluções } \\
\text { modulares em uma base sincronizada }\end{array}$ & $\begin{array}{l}\text { Desfrutam de confiabilidade quanto } \\
\text { aos contratos estabelecidos com seus } \\
\text { clientes } \\
\text { Proporcionam qualidade assegura } \\
\text { às peças/sistemas JIT ou de forma } \\
\text { sincronizada } \\
\text { Foco em um único setor } \\
\text { Flexibilidade operacional e } \\
\text { habilidade de fornecimento direto } \\
\text { Pedido ganhador provavelmente } \\
\text { define-se por: presença global, } \\
\text { especialização em P\&D e ampla } \\
\text { gama de produtos de marca }\end{array}$ \\
\hline \multicolumn{3}{|c|}{ POTENCIAL DE TRANSFERÊNCIA DE VALOR } \\
\hline $\begin{array}{l}\text { Limitada pela baixa capacidade de } \\
\text { criação de valor }\end{array}$ & Probabilidade de ser alta & Probabilidade de ser alta \\
\hline
\end{tabular}

Fonte: Doran (2003).

objetivando atender às necessidades de processos produtivos de diversos setores.

A empresa atua no projeto e fabricação de peças de plástico para segmentos da cadeia produtiva industrial em parceria junto às grandes empresas do cenário mundial, especialmente para o suprimento das montadoras de veículos. Suas atividades abrangem o processo de importação e exportação de produtos, considerando exigências com um padrão internacional.

a) Estratégia de produção e infraestrutura operacional

A estratégia competitiva tem o foco no custodiferenciação, para atender aos requisitos de alta precisão. Essa estratégia tem destacado a empresa no mercado industrial de injeção de peças técnicas, acessórios de bateria e densímetro, com a busca de soluções para otimização dos processos destinados a clientes dos mais diversos segmentos em que há necessidade de injeção de precisão e total controle do processo produtivo.

A estratégia de produção está centrada na qualidade do produto, com a integração da gestão de projetos e processos, em um sistema misto de produção por lote e por encomenda.

A empresa está capacitada com injetoras de 25 a 450 toneladas de fechamento. Além da estrutura 
Quadro 4. Metodologia AGA - SCM na gestão do relacionamento com o cliente.

\begin{tabular}{|l|}
\multicolumn{1}{|c|}{ Eixo - Gestão do relacionamento com o cliente } \\
\hline 1 A empresa faz diferenciação entre clientes, definindo quais são os clientes chave? \\
\hline 2 Tem equipe multifuncional designada para gerenciar o processo de gestão do relacionamento com o cliente? \\
\hline 3 Tem procedimento para relacionamento com clientes, com regras de contrato definidas? \\
\hline $\begin{array}{l}\text { 4 Desenvolve e implementa contratos de fornecimento customizados com os clientes (acordos de produtos e } \\
\text { serviços - PSA)? }\end{array}$ \\
\hline 5 Desenvolve e implementa contratos padrão com clientes (acordos de produtos e serviços - PSA)? \\
\hline 6 Desenvolve programa de melhoria de processos com clientes? \\
\hline 7 Desenvolve esforços, junto aos clientes, para reduzir a variabilidade da demanda? \\
\hline 8 Desenvolve ações, junto aos clientes, para eliminar atividades que não agregam valor? \\
\hline Identifica oportunidades junto aos clientes? \\
\hline 10 Tem diretrizes para compartilhar benefícios de melhorias de processo com clientes? \\
\hline $\begin{array}{l}11 \text { Existe procedimento para analisar o cliente, periodicamente, em relação aos produtos adquiridos, crescimento } \\
\text { das vendas e sua posição no segmento em que atua? }\end{array}$ \\
\hline 12 Existe procedimento para avaliar impacto financeiro do cliente sobre a empresa? \\
\hline 13 Existe procedimento para avaliar impacto financeiro da empresa sobre o cliente? \\
\hline
\end{tabular}

Fonte: Simon (2005).

Quadro 5. Metodologia AGA - SCM na gestão do relacionamento com fornecedores.

\begin{tabular}{|l|}
\hline \multicolumn{1}{|c|}{ Eixo - Gestão do relacionamento com o fornecedor } \\
\hline 1 A empresa faz diferenciação entre fornecedores, definido quais são os fornecedores chave? \\
\hline 2 Tem equipe multifuncional designada para gerenciar o processo de gestão de relacionamento com o fornecedor? \\
\hline 3 Tem procedimento para relacionamento com fornecedores, com regras de contrato definidas? \\
\hline 4 Desenvolve e implementa contratos customizados com fornecedores (acordos de produtos e serviços - PSA)? \\
\hline 5 Desenvolve e implementa contratos padrão com fornecedores (acordos de produtos e serviços - PSA)? \\
\hline 6 Desenvolve programas de melhoria de processo com fornecedores? \\
\hline 7 Existem procedimentos para quantificar os benefícios decorrentes de melhorias de processos? \\
\hline 8 Existem diretrizes para compartilhar benefícios decorrentes das melhorias de processos? \\
\hline 9 Identifica oportunidades junto aos fornecedores chave? \\
\hline 10 Existem relatórios para avaliar custos/lucratividade dos pedidos de compra? \\
\hline 11 Existe procedimento para desenvolvimento e avaliação de fornecedores? \\
\hline $\begin{array}{l}\text { 12 Existe procedimento para analisar o fornecedor, periodicamente, em relação aos produtos adquiridos, } \\
\text { relacionamento e sua posição no segmento em que atua? }\end{array}$ \\
\hline
\end{tabular}

Fonte: Simon (2005).

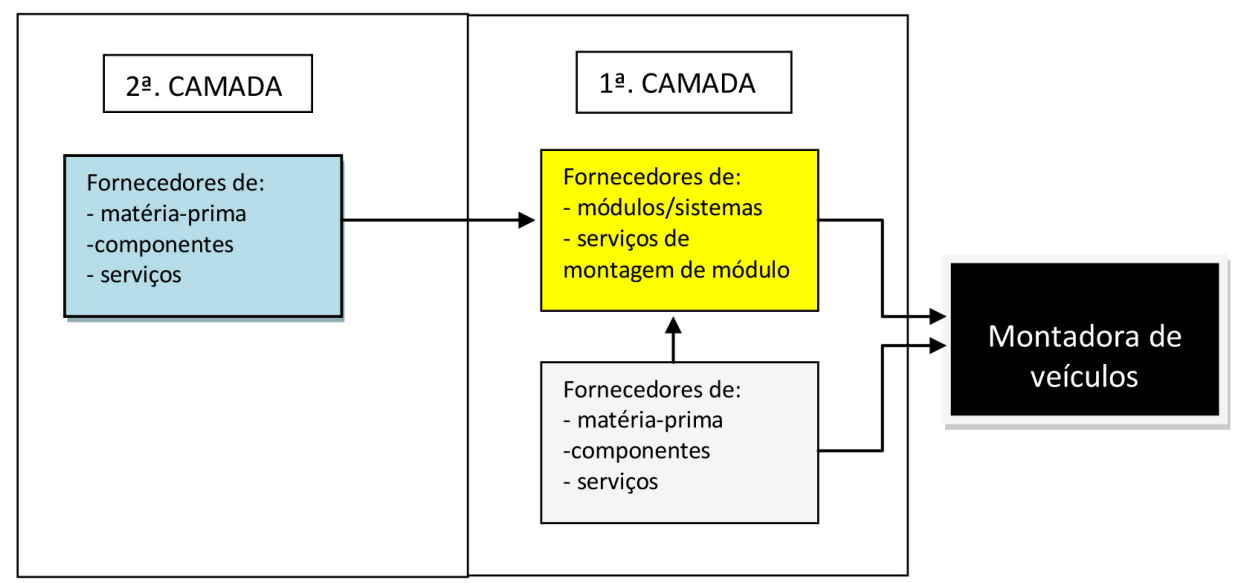

Figura 6. Etapa da cadeia de suprimentos da pesquisa. 
de máquinas, possui diversos equipamentos periféricos como robôs manipuladores, esteiras rolantes, moinhos de baixa rotação, controladores de temperatura até 20 zonas e pontes rolantes em todas as áreas de injeção.

A ferramentaria faz a construção e manutenção de moldes e dispositivos, com o desenvolvimento de projetos que atendam às soluções exigidas no processo de injeção para os novos negócios. O desenvolvimento de moldes e a manutenção também incluem a correção e a modificação de ferramentais.

O controle de processo utiliza um conjunto de instrumentos que permite à empresa dimensionar componentes dos mais variados tipos e graus de dificuldade, sendo que o recurso mais completo é a Tridimensional CNC Mitutoyo modelo C574, que permite a execução de medições diversas através de controle numérico.

Esse equipamento indica que a produção possui um sistema de controle da qualidade automatizado em pontos críticos, o que viabiliza uma inspeção com menor margem de erro e com periodicidade diária.

O laboratório de metrologia e de ensaios conta com programa de ensaios para o preenchimento do prontuário que mantém um nível de qualidade atrelado ao sistema de gestão da qualidade.

\section{b) Gestão da qualidade}

O sistema de qualidade possibilita o controle completo e melhoria contínua de todas as fases do processo produtivo, com constante atualização em tecnologia e certificação pelo Bureau Veritas com os sistemas:

- TS 16949 desde 2008;

- ISO 9000 desde 2005;

- Dun \& Bradstreet - desde a empresa está cadastrada na base mundial de dados com reconhecimento da qualidade internacional.

\section{MISSÃO}

Alocar recursos para tecnologia unindo soluções criativas e desenvolvimento humano, para atender à dinâmica do mercado de injeção plástica.

\section{VISÃO}

Priorizar a excelência de seus produtos e serviços.

$\mathrm{Na}$ aprendizagem organizacional, há um investimento anual para capacitação de colaboradores e desenvolvimento de parcerias com os fornecedores, a fim de assegurar a satisfação dos clientes internos, mantendo os resultados desejáveis.

c) Gestão do relacionamento na cadeia de suprimentos

Os Gráficos 1 e 2 revelam que há muito a ser considerado para uma gestão de relacionamentos mais eficiente e sincronizada com a gestão da cadeia de suprimentos.
O Gráfico 1 mostra que o relacionamento com o cliente, que no caso são os fornecedores de módulos das montadoras, possui como pontos fortes:

- Contratos padrão com o cliente (acordo de produtos e serviços);

- Programa de melhoria de processo com o cliente;

- Compartilhamento de benefícios de melhorias de processo com o cliente;

- Avaliação do impacto financeiro do cliente sobre a empresa.

Como ponto a ser melhorado, sugere-se o desenvolvimento de ações junto aos clientes para eliminar atividades que não agregam valor, proporcionando uma relação que estimule a melhoria contínua e a fidelização do cliente.

O Gráfico 2 indica que o relacionamento com os fornecedores, que no caso são os fabricante e

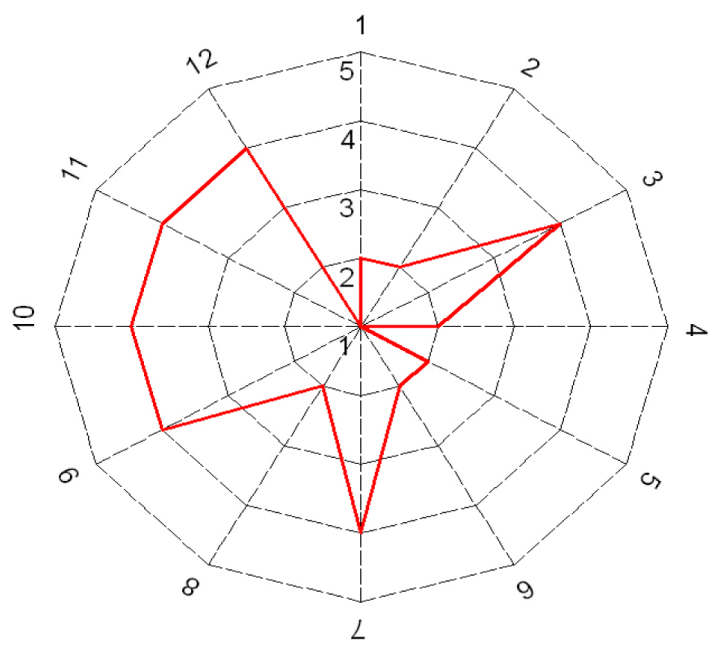

Gráfico 1. Gestão de relacionamento com o fornecedor.

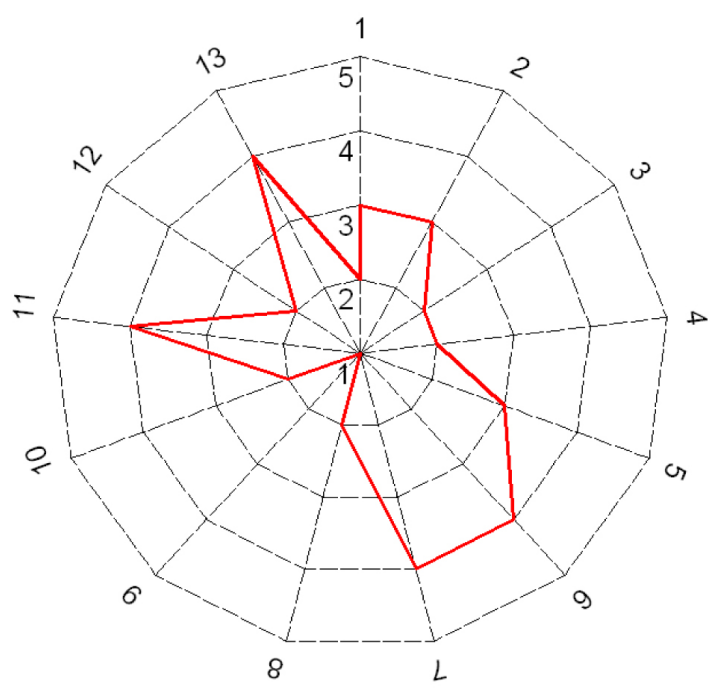

Gráfico 2. Gestão de relacionamento com o cliente. 
distribuidores de resina e de acessórios, possui como pontos fortes:

- Equipe multifuncional designada para gerenciar o processo de gestão de relacionamento com o fornecedor;

- Procedimentos para quantificar os benefícios decorrentes de melhoria de processo;

- Identificação de oportunidades junto aos fornecedores chave, relatórios para avaliar custos/lucratividade dos pedidos de compra e procedimento para desenvolver;

- Avaliação de fornecedores.

Como pontos de melhoria destacam-se: a necessidade de desenvolvimento e implementação de contratos customizados com os fornecedores e procedimento para avaliar o fornecedor, periodicamente, em relação aos produtos adquiridos, relacionamento e sua posição no segmento em que atua.

A diretoria tem interesse em manter a empresa alinhada estrategicamente com seus clientes e fornecedores. Essa percepção é observada em algumas iniciativas e práticas desenvolvidas na unidade produtiva.

Um dessas práticas é o incentivo à visita dos clientes ao processo de produção, para proporcionar uma interface mais aberta, que possa viabilizar mais confiança nas relações cultivadas entre cliente e fornecedor. Em dezembro de 2010, grandes clientes (empresas) de Manaus, do Japão e da Finlândia visitaram e auditaram o sistema de qualidade da planta de São Paulo, aprovando o desenvolvimento de novos produtos e o controle de processo apresentado.

Outro exemplo aconteceu em novembro de 2010: os técnicos em plásticos e os mecânicos de manutenção participaram do Treinamento Arburg, que teve a finalidade de aprimorar conhecimentos sobre os equipamentos da marca, estreitando a relação entre fornecedor e cliente.

\section{Considerações finais}

A gestão da cadeia de suprimentos no setor automotivo é referência para outros setores em termos de práticas e iniciativas. Na gestão do relacionamento do fornecedor com a líder da cadeia, a montadora, observa-se a aplicação de conceitos e ferramentas que têm gerado uma reestruturação e consolidação na base de fornecedores.

Mas essa relação de integração na cadeia depende do nível de interface do fornecedor com a montadora. O primeiro nível é considerado estratégico e tem a função de liderar a base de fornecedores que irá fabricar o seu módulo.

A empresa em estudo atua no fornecimento de peças para o sistemista e embora não esteja trabalhando diretamente para a montadora, sofre plena influência da sua governança na gestão da cadeia de suprimentos. Devido a seu pequeno porte e por participar da segunda camada de suprimentos, mostrada na Figura 6, essa empresa tem um baixo poder de negociação junto a seu cliente, que é fornecedor sistemista da montadora de veículos. Isso indica que as condições de preço, qualidade e entrega são determinadas pelo cliente, explicando por que a gestão do relacionamento com o cliente é bem mais formal e estruturada do que a gestão do relacionamento com os fornecedores.

Na gestão do relacionamento com seus fornecedores, os resultados desse estudo revelam que há vários aspectos gerenciais que distanciam essa empresa de uma gestão da cadeia mais eficiente devido à limitada colaboração no processo de comunicação com suas parceiras, visto que grande parte de suas atividades ainda são informais ou estão sendo realizadas sem planejamento conjunto com seus parceiros. Como cliente, a empresa analisada tem baixo poder de negociação porque lida principalmente com o setor petroquímico, empresas de grande porte que fornecem plásticos em grânulos para o processo de injeção.

Essas questões afetam a eficiência e a eficácia da gestão da cadeia de suprimentos, de modo que esta pesquisa auxilia no mapeamento dessa gestão, permitindo a identificação dos pontos fortes e dos pontos que podem ser melhorados no relacionamento dessa indústria com seus fornecedores e clientes.

\section{Referências}

ALVES FILHO, A. G. et al. Pressupostos da gestão da cadeia de suprimentos: evidências de estudos sobre a indústria automobilística. Gestão \& Produção, v. 11, n. 3, set./dez. 2004. http://dx.doi.org/10.1590/ S0104-530X2004000300003

BERTAGLIA, P. R. Logística e gerenciamento da cadeia de abastecimento. 2. ed. rev. São Paulo: Saraiva, 2009.

BINDER, M.; CLEGG, B. Designing and managing collaborative enterprises in the automotive industry. International Journal of Logistics, Research and Applications, v. 10, n. 2, jun. 2007.

CERRA, A. L.; MAIA, J. L.; ALVES FILHO, A. G. Aspectos estratégicos, estruturais e relacionais de três cadeias de suprimentos automotivas. Gestão \& Produção, v. 14, n. 2, 2007. http://dx.doi.org/10.1590/ S0104-530X2007000200005

CHOPRA, S.; MEINDL, P. Gerenciamento da cadeia de suprimentos: estratégia, planejamento e operação. São Paulo: Prentice Hall, 2003.

COOPER, M. C.; LAMBERT, D. M.; PAGH, J. D. Supply Chain Management: More than a new name for logistics. International Journal of Logistics Management, v. 8, n. 1, p. 1-13, 1997.

CORREA, H. L.; CORREA, C. A. Administração da produção e operações: manufatura e serviços. 2. ed. São Paulo: Atlas, 2006. 
COUSINS, P. et al. Strategic supply management: principles, theories and practice. England: Pearson Education, 2008.

DINIZ, J. D. A. S.; FABBE-COSTES, N. Supply chain management and supply chain orientation: key factors for sustainable development projects in developing countries? International Journal of Logistics, Research and Applications, v. 10, n. 3, set. 2007.

DORNIER, P. et al. Logística e operações globais: texto e casos. São Paulo: Atlas, 2000.

GRAZIDIO, T. Estudo comparativo entre os fornecedores de componentes automotivos de plantas convencionais e modulares. 2004. Tese (Doutorado em Engenharia de Produção)-Escola Politécnica, Universidade de São Paulo, São Paulo, 2004.

HALL, D.; BRAITHWAITE, A. The development of thinking in supply chain and logistics management. In: BREWER, A. M.; BUTTON, K. J.; HESNER, D. A. Handbook of logistics and supply-chain management. Oxford: Pergamon, 2001.

HINES, T. Supply chain strategies: customer-driven and customer-focused. Elsevier Ltd., 2004

HULT, G. T. M.; KETCHEN JUNIOR, D. J.; ARRFELT, M. Strategic supply chain management: improving performance through a culture of competitiveness and knowledge. Strategic Management Journal, v. 28, p. 1035-1052, 2007. http://dx.doi.org/10.1002/smj.627

JOSHI, M. P.; KATHURIA, R.; PORTH, S. J. Alignment of strategic priorities and performance: an integration of operations and strategic management perspectives. Journal of Operations Management, v. 21, 2003, p. 353-369. http://dx.doi.org/10.1016/ S0272-6963(03)00003-2

KAKABADSE, A; KAKABADSE, N. Smart sourcing: international best practice. New York-Hampshire: Palgrave, 2002.

KOTZAB, H. et al. Research methodologies in supply chain management. Germany: Physica-verlag, 2005. http://dx.doi.org/10.1007/3-7908-1636-1

LAMBERT, D. M.; COOPER, M. C.; PAGH, J. D. Supply chain management: implementation issues and research opportunities. International Journal of Logistics Management, v. 9, n. 2, p. 1-19, 1998a. http://dx.doi. org/10.1108/09574099810805807

LAMBERT, D. M.; STOCK, J. R.; ELLRAM, L. M. Fundamentals of logistics management. Boston: Irwin/McGraw-Hill, 1998b.

LAMBERT, D. M.; STOCK, J. R.; VANTINE, J. G. Administração estratégica da logística. São Paulo: Vantine Consultoria, 1998c.

MARTINS, P. G.; ALT, P. R. C. Administração de materiais e recursos patrimoniais. São Paulo: Saraiva, 2009.

MIN, S. et al. Supply chain collaboration: what's happening? The International Journal of Logistics Management, v. 7, n. 2, p. 237-256, 2005. http://dx.doi. org/10.1108/09574090510634539

MONCZKA, R.; TRENT, R.; HANDFIELD, R. Purchasing and supply chain management. 2 nd ed. Ohio: SouthWestern - Thomson Learning, 2002.

MOURA, L. R. Gestão do relacionamento com fornecedores: análise da eficácia de programa para desenvolvimento e qualificação de fornecedores para grandes empresas. 2009. Tese (Doutorado em Engenharia de Produção)-Escola Politécnica, Universidade de São Paulo, São Paulo, 2009.

PIRES, S. R. I. Gestão da cadeia de suprimentos (supply chain management): conceitos, estratégias, práticas e casos. 2. ed. São Paulo: Atlas, 2009.

PRIETO, E.; MIGUEL, P. A. C. Consolidação da cadeia modular automotiva e a progressividade na transferência de valor no desenvolvimento de produto entre os fornecedores estratégicos e de segundo nível: um caso exploratório. In: ENCONTRO NACIONAL DE ENGENHARIA DE PRODUÇÃO, 26., 2006, Fortaleza. Anais... Fortaleza, 2006.

SHETH, J. N.; SHARMA, A. Relationship management. In: MENTZER, J. T.; MYERS, M. B.; STANK, T. P. Global supply chain management. California: Sage Publications Inc., 2007.

SIMON, A. T. Uma metodologia para avaliação do grau de aderência das empresas a um modelo conceitual de gestão da cadeia de suprimentos. 2005. Tese (Doutorado em Engenharia de Produção)-Universidade Metodista de Piracicaba, Santa Bárbara D’Oeste, 2005.

SLACK, N.; CHAMBER, S.; JOHNSTON, R. Administração da produção. 3. ed. São Paulo: Atlas, 2009.

SPEKMAN, R. E.; KAMAUFF JUNIOR, J. W.; MYHR, N. An empirical investigation into supply chain management: a perspective on partnerships. International Journal of Physical Distribution \& Logistics Management, v. 29, n. 8, 1998.

STEPHENS, S. Supply chain council \& supply chain operations reference (SCOR) model overview. 2001. Disponível em: <http://www.athabascau.ca/scm/pdf10-02/ SCOR_ReferenceModel.pdf>. Acesso em: maio 2011.

SUPPLY CHAIN COUNCIL - SCC. Supply chain operations reference (SCOR) model. Disponível em: $<$ http://supply-chain.org/f/SCOR-Overview-Web.pdf >. Acesso em: 03 maio 2011.]

SUZIGAN, S.; GARCIA, R.; FURTADO, J. Estruturas de governança em arranjos ou sistemas locais de produção. Revista Gestão \& Produção, v. 14, n. 2, p. 425-439, 2007.

TOWILL, D. R.; CHILDERHOUSE, P.; DISNEY, S. M. Integrating the automotive supply chain: where are we now? International Journal of Physical Distribution \& Logistics Management, v. 32, n. 2, p 79-95, 2002. http://dx.doi.org/10.1108/09600030210421705

VIVALDINI, M; PIRES, S. R. I. Operadores logísticos: integrando operações em cadeias de suprimentos. São Paulo: Atlas, 2010.

ZHANG, C.; VISWANATHAN, S.; HENKE JUNIOR, J. W. The boundary spanning capabilities of purchasing agents in buyer-supplier trust development. Journal of Operations Management, v. 29, p. 318-328, 2011. http://dx.doi.org/10.1016/j.jom.2010.07.001

ZIRPOLI, F.; CAPUTO, M. The nature of buyer-supplier relationships in co-design activities. International Journal of Operations \& Production Management, v. 22 , n. 12 , p. 1389-1410, 2002. http://dx.doi. org/10.1108/01443570210452066 
